\title{
Brinquedotecas hospitalares em Belém: Criação, espaço e funcionamento
}

\author{
Hospital toy library in Belem, Para State, Brazil: Creation, space and operation
}

Mayara Barbosa Sindeaux Lima ${ }^{[a]}$, Celina Maria Colino Magalhães ${ }^{[b]}$

\footnotetext{
${ }^{[a]}$ Mestranda do Programa de Pós-Graduação em Teoria e Pesquisa do Comportamento da Universidade Federal do Pará (UFPA), Marabá, PA - Brasil, e-mail: mayarasindeaux@gmail.com

${ }^{[b]}$ Doutora em Psicologia pela Universidade de São Paulo (USP), Docente do Programa de Pós-Graduação em Teoria e Pesquisa do Comportamento da Universidade Federal do Pará (UFPA), Belém, PA -

Brasil, e-mail:

celina.magalhaes@pq.cnpq.br
}

Recebido: $11 / 08 / 2011$

Received: 08/11/2011

Aprovado: 16/11/2011 Approved: 11/16/2011

\section{Resumo}

A brinquedoteca hospitalar é um direito assegurado às crianças por meio da Lei n. 11.104/051, entretanto ainda não foi concretizado integralmente no país. Este estudo objetivou descrever e analisar as condições de serviços e espaços disponibilizados pelas brinquedotecas hospitalares em Belém do Pará. Fizeram parte da pesquisa quatro hospitais que possuem este serviço. Os dados foram coletados por meio de entrevistas individuais com dez técnicos, observações dos atendimentos e registro fotográfico. Dentre os principais resultados encontrados estão: (a) todos os hospitais eram públicos; (b) existem poucos registros acerca da implantação e funcionamento desses espaços; (c) no tocante ao acervo lúdico, este se diferenciou em relação à quantidade; (d) as equipes apresentam composição diferenciada em relação ao número de membros e formação; (e) são oferecidas atividades livres e dirigidas. 0 estudo permitiu verificar aspectos que favorecem a concretização dos objetivos de uma brinquedoteca e reflexões sobre possibilidades de melhorias.

Palavras-chave: Criança hospitalizada. Cumprimento da lei. Assistência hospitalar.

\section{Abstract}

The hospital toy library is a right granted to children through Law 11.104/05, though it's not yet fully implemented in the country. This study was aimed at describing and analyzing the conditions of services and spaces made available by the hospital toy library in Belem, Para State, Brazil. Four hospitals with this service participated in the study. Data were collected through individual interviews with 10 technicians, observation of the service and photographic record. The main results found are: (a) all the hospitals with toy library were public; (b) there are few records regarding the deployment and operation of these spaces; (c) regarding the collection of toys, it differed in quantity; (d) teams present different compositions in relation to the number of members and to their education; (e) free and

\footnotetext{
1 A Lei n. 11.104, de março de 2005, dispõe sobre a obrigatoriedade de instalação de brinquedotecas nas unidades de saúde que ofereçam atendimento pediátrico em regime de internação. Para efeitos da Lei, a brinquedoteca é o espaço provido de brinquedos e jogos educativos, destinado a estimular as crianças e seus acompanhantes a brincar. Dessa forma, a Lei n. 11.104/05 é um marco na luta em favor dos direitos da criança hospitalizada e de seu desenvolvimento integral
} 
targeted activities are offered. This study allowed us to show aspects that promote the achievement of the objectives in toy library and reflections on possible improvements.

Keywords: Hospitalized child. Law enforcement. Hospital care.

\section{Introdução}

A literatura aponta a hospitalização como um evento potencialmente estressante à criança e sua família, pois, somada à fragilidade física provocada pelo próprio adoecer, há o estranhamento diante dos instrumentos hospitalares, a submissão a procedimentos médicos invasivos e a limitação de movimentos, bem como, uma brusca mudança de hábitos e costumes (Mitre \& Gomes, 2007).

Quando brinca no hospital, a criança modifica o ambiente em que se encontra, tornando-o mais familiar, pois pode desempenhar uma atividade rotineira e prazerosa do seu cotidiano. A identificação por parte da criança de que ela é capaz e de alterar esse novo ambiente, produzindo um estado de relaxamento e liberdade, favorece a integração de aspectos negativos e positivos da hospitalização (Carvalho \& Begnis, 2006; Oliveira, Gabarra, Marcon, Silva \& Macchiaverni, 2009).

Dentro do hospital, a brincadeira pode ser favorecida pela implantação da brinquedoteca, um ambiente alegre, colorido, agradável e seguro que surgiu com a finalidade de resgatar o brincar livre e espontâneo (Cunha, 2007; Magalhães \& Pontes, 2002; Romano \& Faria, 2008). Este espaço é garantido pela Lei n. 11.104/2005 e sua inobservância se configura em infração à legislação sanitária federal.

A criação de uma brinquedoteca hospitalar deve ocorrer dentro de um enfoque técnico que lhe garanta confiabilidade, segurança e suporte para suas ações (Oliveira, 2008). Entretanto, em muitos casos as brinquedotecas são implantadas sem que haja um planejamento formal, o que pode comprometer seu funcionamento. Assim, algumas precauções devem ser tomadas, como: ter apoio da direção do hospital, delinear os objetivos da brinquedoteca e estudo das condições físicas mais adequadas (Dietz \& Oliveira, 2008; Macedo, 2008; Magalhães \& Pontes, 2002).

Após a implantação desses espaços, alguns aspectos devem ser considerados para garantir sua manutenção e qualidade, como a participação da família e prevenção da contaminação hospitalar
(Viegas \& Cunha, 2008). Freitas, Silva, Carvalho, Pedigone e Martins (2007), após avaliarem a presença de bactérias nos brinquedos de uma brinquedoteca hospitalar e seu perfil de resistência às drogas, concluíram que os riscos de uma infecção cruzada são evidentes e que, portanto, medidas preventivas são essenciais.

Outro aspecto fundamental diz respeito a quem atuará nela, além de ser um parceiro na brincadeira, o brinquedista deve estimular comportamentos lúdicos e auxiliar a clientela a entender o que está acontecendo consigo e a sua volta. Para isso, é necessário ter clareza quanto ao perfil da clientela, ao uso dos brinquedos e espaço, bem como à reserva de um horário para a formação, avaliação e planejamento (Cunha, 2007; Dietz \& Oliveira, 2008; Magalhães \& Pontes, 2002; Viegas \& Cunha, 2008).

Em pesquisas desenvolvidas por Dietz e Oliveira (2008) e Oliveira (2010) a fim de analisar brinquedotecas hospitalares em relação a critérios de qualidade em cidades paulistas, verificou-se o descumprimento da Lei n. 11.104/05. Nas instituições em que havia esses espaços, foram realizadas observações, entrevista e aplicação da Escala Autoavaliativa de Índices de Qualidade com os seus responsáveis. Foram encontrados aspectos positivos, particularmente, os serviços oferecidos e a acolhida à clientela; porém, alguns foram insatisfatórios, como a formação profissional da equipe.

Desse modo, apesar dos avanços representados pela Lei n. 11.104/05, ainda é comum encontrar instituições sem esses espaços. Além disso, a legislação oferece poucos parâmetros à sua estruturação e funcionamento. Nesse sentido, existe a necessidade de se atentar para a qualidade das brinquedotecas a fim de que sua filosofia seja preservada (Oliveira, 2005).

Pesquisas sobre essa temática podem contribuir para um conhecimento científico desse contexto e oferecer indicativos para a elaboração de parâmetros para sua implantação e avaliação. Diante disso, o objetivo deste estudo foi traçar um panorama da criação e das condições de serviços e espaços oferecidos pelas brinquedotecas hospitalares belenenses. 


\section{Metodologia}

Participantes

Foram entrevistados dez técnicos que estavam em exercício nas brinquedotecas hospitalares belenenses, distribuídos da seguinte forma: na primeira instituição participaram dois terapeutas ocupacionais e uma pedagoga, respectivamente, P1A, P1B, P1C; na segunda, uma psicóloga e duas terapeutas ocupacionais, P2A, P2B e P2C, respectivamente; na terceira, duas pedagogas, P3A e P3B; e na quarta, duas terapeutas ocupacionais, $\mathrm{P} 4 \mathrm{~A}$ e $\mathrm{P} 4 \mathrm{~B}$.

\section{Ambiente}

Quatro hospitais que haviam implantado brinquedotecas; para resguardar suas identidades, foram utilizados os códigos: H1, H2, H3 e H4.

\section{Instrumentos e material}

Utilizou-se um roteiro de entrevista semidirigida com o objetivo de obter informações sobre o histórico da brinquedoteca, seu espaço e funcionamento, composto por 12 tópicos elaborados pelos pesquisadores. Além de um Roteiro de Observação a fim de coletar informações sobre o espaço e funcionamento.

\section{Procedimento}

Após a aprovação do projeto no Comitê de Ética de Pesquisas com Seres Humanos do Instituto de Ciências da Saúde/UFPa (protocolo 068/09), foi feito um levantamento no Cadastro Nacional de Estabelecimentos de Saúde (Brasil, 2010) das unidades que ofereciam internação pediátrica na cidade de Belém, sendo encontradas 32. Por meio de contato telefônico, verificou-se que cinco ofereciam o serviço de brinquedoteca. Destas, quatro permitiram a realização da pesquisa.

Antes de se iniciar a coleta de dados, foram realizadas a entrega e a leitura do Termo de Consentimento Livre e Esclarecido (TCLE) com os técnicos que atuavam no espaço. Nesse momento foram explicitados os objetivos do estudo, o sigilo das informações coletadas, assim como o esclarecimento de algumas dúvidas. Após a assinatura do TCLE, aplicou-se o Roteiro de Entrevista semidirigida, individualmente, em uma sala reservada ou na brinquedoteca, caso esta tivesse fechada aos usuários.

Foram realizadas, ao menos, cinco observações, sendo finalizadas quando todos os itens do Roteiro de Observação tinham sido contemplados; a duração da sessão variou entre 90 a 120 minutos.

\section{Análise dos dados}

Os dados foram organizados por hospital segundo três dimensões de análise: histórico, espaço e funcionamento. Foi realizada análise qualitativa segundo Minayo (2000), sendo averiguadas as semelhanças e peculiaridades entre o relato verbal intra e interinstituição, e confrontando-os com os dados obtidos por meio de observação.

\section{Resultados}

HI

\section{Histórico}

0 espaço foi implantado em 2006, época em que os participantes ainda não eram funcionários do referido hospital, e, portanto, estiveram ausentes desse processo. Segundo os participantes, foi elaborado um projeto de implantação que incluía aspectos de infraestrutura e acervo lúdico. Entretanto, estes deram informações inconsistentes ao serem questionados se houve um levantamento das demandas à brinquedoteca e se o projeto continha uma descrição de como esta deveria ser organizada e como funcionaria.

0 projeto foi enviado a uma empresa que custeou a estrutura física, os materiais lúdicos e os de escritório, ficando sob responsabilidade do hospital a lotação e remuneração de pessoal, o que foi efetivado por meio de concurso público.

\section{Espaço}

A brinquedoteca foi construída como um anexo a uma das enfermarias pediátricas, tendo dois pisos. 0 térreo é de piso grosso e sem paredes, apenas 
colunas, há ainda uma área arborizada, com chão de terra e alguns equipamentos como balanços e gangorras; nesse espaço são realizadas celebrações de datas festivas. 0 andar superior é um espaço fechado, em cuja área de $65,66 \mathrm{~m}^{2}$ estão dispostos o acervo lúdico, os equipamentos e o material administrativo; a entrada é realizada pela enfermaria citada anteriormente. No tocante à iluminação e à ventilação, o espaço dispõe tanto da natural quanto da artificial.

A brinquedoteca conta com três estantes, sem portas, com altura é de $107 \mathrm{~cm}$. São disponibilizados brinquedos de faz de conta, de construção e jogos de regras; não há jogos eletrônicos e acesso à internet. Observou-se que os brinquedos que apresentavam peças pequenas e/ou móveis estavam dispostos na prateleira superior e em cima de um armário. 0 espaço também possui televisão, DVD, uma estante de livros, conjuntos de mesas e cadeiras.

A divulgação do espaço é feita por meio do convite dos técnicos, de uma placa de inauguração e pela visualização da própria brinquedoteca, propiciada pelo vidro transparente da porta. As crianças que se encontram na enfermaria em que foi construído o anexo podem ir a ele espontaneamente, caso não apresentem restrição ao leito. 0 acesso daquelas crianças que se encontram nas outras enfermarias é restrito, sendo realizado, em geral, por meio de convite dos técnicos.

\section{Funcionamento}

A clientela atendida é composta por pacientes pediátricos, em geral de zero a 12 anos, e seus acompanhantes, oriundos de todo o estado. Em relação à patologia, ela corresponde em sua maioria a problemas respiratórios, renais e gástricos; são atendidas também crianças submetidas a cirurgias eletivas e vítimas de escalpelamento ou abuso sexual.

No início do estudo, seis pessoas compunham a equipe, sendo apenas um do sexo masculino. No que se refere ao vínculo profissional dos que trabalhavam na brinquedoteca, quatro eram funcionários concursados: uma pedagoga, dois terapeutas ocupacionais e uma auxiliar de limpeza; também havia duas bolsistas, estudantes de graduação, no entanto, o contrato de bolsas expirou sem que fosse renovado.
Segundo o relato dos participantes, não há a figura do coordenador e a equipe está dividida em dois turnos. Além disso, constatou-se a falta de reuniões periódicas. A troca de informações ocorre, em geral, informalmente por meio de um diário e dos profissionais que atuam em dois turnos.

No que diz respeito à realização de atividades, o espaço abre em dois turnos, de segunda a sexta-feira, sendo oferecidas atividades livres e dirigidas. De acordo com os participantes, as atividades direcionadas não se tornam empecilho ao livre brincar, pois é permitido à clientela decidir se quer participar, sem qualquer represália. Além disso, a equipe realiza celebração de datas festivas.

No tocante à higienização, os brinquedos são limpos com água e detergente ou álcool 70\%.

\section{$\mathrm{H} 2$}

\section{Histórico}

A brinquedoteca iniciou suas atividades em 2002. Entretanto, o espaço físico já funcionava como local de recreação e havia sido planejado durante a elaboração do projeto arquitetônico do prédio hospitalar. Os participantes afirmaram desconhecer se houve algum tipo de levantamento de demandas ao espaço e/ou elaboração de projeto que contemplasse aspectos além dos estruturais; destacaram ainda que não exerciam atividade profissional no $\mathrm{H} 2$ nesse período.

A brinquedoteca é um dos oito subprojetos voltados à clientela infantil do hospital, os quais foram escritos em 2006. Desde 2009 o projeto está em fase de atualização devido à entrada de novos profissionais (assistente social e pedagogo); contudo, até o final da coleta de dados o mesmo não havia sido concluído.

\section{Espaço}

O espaço, tendo uma área é de $41,9 \mathrm{~m}^{2}$, foi construído no $2^{\circ}$ andar, onde se encontra a clínica pediátrica. A respeito da iluminação e ventilação, é feito uso tanto da natural quanto da artificial.

Em relação ao acervo lúdico, há uma estante com brinquedos, com altura de $216 \mathrm{~cm}$. Além disso, há materiais lúdicos no chão, próximo às paredes. 
São disponibilizados jogos de regras, brinquedos de faz de conta, de construção e sonoros, estando ausentes jogos eletrônicos, computadores e acesso à internet. Observou-se que os brinquedos com peças pequenas e móveis estavam alocados na parte superior da estante. 0 espaço conta ainda com uma televisão, DVD, uma estante com livros infantis, conjuntos de mesas e cadeiras.

A divulgação é feita por meio do convite dos técnicos, de uma placa e pela própria visualização do espaço, já que há na porta um vidro transparente. 0 espaço também é diferenciado na sua parte externa, onde há desenhos de crianças brincando ao ar livre. Como o espaço está inserido dentro da clínica pediátrica, a clientela tem livre acesso a ela, desde que não haja restrição ao leito.

\section{Funcionamento}

A clientela infantil está na faixa etária de zero a 12 anos, mas pode se estender até os 15 anos. A maioria das crianças hospitalizadas, oriundas de todo o estado, estão em tratamento cardiológico e aguardam cirurgia.

A respeito da equipe, os participantes afirmaram que esta é composta por: uma psicóloga, duas terapeutas ocupacionais, sendo uma docente, portanto, sem vínculo empregatício com o $\mathrm{H} 2$, uma assistente social, uma pedagoga, quatro auxiliares de reabilitação e os estagiários de terapia ocupacional. A equipe está dividida em dois turnos, sendo que a troca de informações sobre a clientela, a avaliação e o planejamento das atividades ocorrem, em geral, informalmente e pelo uso de livros de ocorrência.

Verificou-se que os técnicos se organizam em equipe de um projeto do qual a brinquedoteca faz parte. Provavelmente por isso os participantes citaram a assistente social como membro da equipe, apesar de suas atividades serem desenvolvidas fora do espaço. Outro aspecto observado é que nessa instituição está ausente a figura do coordenador.

Em relação às atividades realizadas, os participantes destacaram que são oferecidas tanto as dirigidas quanto as livres, cabendo à clientela escolher em que atividade participar sem qualquer forma de represália; além disso, são comemoradas datas festivas. 0 espaço funciona todos os dias da semana em dois turnos.
No que se refere à higienização, a limpeza dos brinquedos é feita com água e sabão e/ou álcool 70\%.

H3

\section{Histórico}

A brinquedoteca foi construída há aproximadamente 10 anos, mas o hospital dispunha antes de uma sala de recreação em outra dependência da instituição. Apesar de P3A atuar nesse espaço, afirmou não ter participado da confecção do projeto da brinquedoteca.

Sobre um possível levantamento prévio das demandas a serem atendidas na brinquedoteca, uma das participantes relatou desconhecer se houve essa análise, justificando que nesse período exercia suas atividades profissionais fora do hospital; outra participante verbalizou que isso não ocorreu.

\section{Espaço}

Esse hospital é o único cuja brinquedoteca caracteriza-se como ambulatorial. 0 espaço tem $41,4 \mathrm{~m}^{2}$ e dispõe de duas estantes, sem portas, com 2,15 m de altura, nelas estão postos brinquedos, como os de construção, faz de conta e jogos de regras; também há brinquedos no chão. Os jogos com peças pequenas e móveis ficam na parte superior da estante ou dentro de um dos armários. A brinquedoteca dispõe ainda de aparelho de TV, DVD, conjunto de mesas e cadeiras, computadores, jogos eletrônicos e videogame, mas sem acesso à internet.

A divulgação do espaço é feita pelo convite dos técnicos, por meio de uma placa na porta, acrescido a isto, há duas janelas de vidro transparente que permitem a visualização do espaço. Além disso, o setor de quimioterapia apresenta decoração diferenciada dos demais, com desenhos e gravuras coladas nas paredes e portas.

Segundo os participantes, os pacientes atendidos no andar em que se encontra a brinquedoteca têm livre acesso ao espaço e, frequentemente, o fazem enquanto aguardam consulta, submissão de exames ou tratamento. Já as crianças que se encontram no Hospital Dia podem se deslocar à brinquedoteca desde que estejam liberados pela equipe de enfermagem desse setor. 


\section{Funcionamento}

A clientela é composta, em sua maioria, de pacientes pediátricos em tratamento oncológico, mas por causa de seu caráter ambulatorial o espaço recebe também crianças que são familiares do paciente e os respectivos responsáveis. Os pacientes são oriundos de todo o estado e de diversas classes sociais.

A brinquedoteca dessa instituição faz parte de um projeto que inclui também a classe hospitalar, cuja coordenação estava sob responsabilidade de duas pedagogas; devido à obtenção de licença de uma delas, apenas uma participou da pesquisa. Além disso, a equipe conta com uma brinquedista, com formação em pedagogia, responsável pela organização do espaço, desenvolvimento de atividades e orientação quanto ao uso dos brinquedos e do espaço.

Durante as entrevistas, as participantes se referiram ao projeto constantemente e, ao serem solicitadas a falar acerca da equipe, estas mencionaram as professoras, que durante a coleta de dados estavam desenvolvendo suas atividades somente na sala de aula. No que diz respeito a reuniões, as técnicas afirmaram que estas objetivam planejamento de atividades e avaliação, não sendo abordados estudo de caso e discussão teórica.

No tocante às atividades desenvolvidas, elas incluem o brincar livre e dirigido, passeios e comemoração de datas festivas. 0 espaço funciona em dois turnos de segunda a sexta-feira e realiza empréstimo de brinquedos a crianças internadas.

Em relação à higienização dos brinquedos, ela é feita com o uso de álcool 70\%.

H4

\section{Histórico}

A brinquedoteca foi criada no ano 2000; nesse período somente a $\mathrm{P} 4 \mathrm{~A}$ atuava no hospital, exercendo a docência. A participante P4B afirmou ter poucas informações sobre o processo de criação do espaço. Houve discordância entre as participantes no que se refere à realização de um levantamento de demandas e à elaboração de um projeto de implantação.

De acordo com P4A, profissionais da Assistência Social do $\mathrm{H} 4$ procuraram um espaço em que a brinquedoteca pudesse funcionar e solicitaram-no à direção do hospital, que cedeu o espaço e um aparelho de som, e as técnicas adquiriram os brinquedos, mesas e cadeiras por meio de doações.

\section{Espaço}

As participantes fizeram críticas ao espaço onde a brinquedoteca está situada porque o espaço é externo ao edifício do hospital e havia sido planejado para ser uma lanchonete. Contudo, afirmam que este foi o local que permitiu efetivar sua implantação.

O local onde a brinquedoteca está inserida é arborizado e ao lado dele há um aparelho com balanço, escada e escorregador. A brinquedoteca pode ser dividida em área interna e externa, com respectivamente $22,3 \mathrm{~m}^{2}$ e $30,5 \mathrm{~m}^{2}$. Na primeira ficam guardados os brinquedos, as mesas e cadeiras, sendo delimitada por paredes e um portão. Durante o funcionamento, alguns conjuntos de mesa são dispostos na área externa, que é aberta e demarcada por um cercado de madeira.

A divulgação do espaço é feita por meio de convite dos técnicos e de sua própria visualização, já que a pintura externa nas cores rosa e azul e o cercado colorido, contrasta com o branco do prédio hospitalar e lhe dá um aspecto lúdico.

O espaço dispõe de dois armários com altura é de $65 \mathrm{~cm}$. Em cima destes e no chão são dispostos brinquedos de faz de conta, de construção, sonoros e jogos com regras. No entanto, estão ausentes computadores, acesso à internet e livros; segundo os participantes, anteriormente livros eram disponibilizados, mas mofaram e não foram substituídos.

0 acesso da clientela à brinquedoteca é reduzido tanto por questões clínicas quanto estruturais, tendo em vista que, na área que as crianças precisam percorrer para chegar ao local existem pacientes aguardando atendimento ambulatorial em várias especialidades; a distância aumenta a dificuldade para se andar com suporte para soro e drenos; são inexistentes rampas da enfermaria pediátrica ao térreo, a área também carece de equipamentos próximos à brinquedoteca, como balão de oxigênio.

\section{Funcionamento}

A clientela atendida é composta de crianças de zero a 12 anos que, em sua maioria, estão com 
alguma doença infectocontagiosa ou parasitária, e seus acompanhantes, oriundos de todo o estado e de várias classes sociais.

Em relação ao pessoal, a coordenação é exercida por P4A, sendo que P4B estava desenvolvendo, junto a seus alunos de estágio supervisionado, atividades lúdicas no espaço. Entretanto, não se configuram como equipe, já que somente a primeira tem vínculo com o hospital e o estágio desenvolvido por um período de apenas dois meses abrange outras enfermarias além das pediátricas.

No tocante ao planejamento a longo prazo, tem sido desenvolvido um projeto que expande as atividades da brinquedoteca por meio de eventos socioculturais, os quais ocorrem mensalmente e envolvem profissionais de diferentes áreas. A rotina de funcionamento é semanal e em um turno, como se verifica no discurso de P4A: "[devido a] brinquedoteca ser externa ao espaço da internação, não tem como a gente dispor pra criança estar lá todo dia ... porque nós não temos pessoal suficiente". As atividades podem ser livres ou dirigidas e são desenvolvidas dentro do estágio supervisionado; além disso, a brinquedoteca oferece empréstimo de brinquedos.

Em relação à higienização, a participante $\mathrm{P} 4 \mathrm{~A}$ verbalizou ter tido dificuldades para que a limpeza dos brinquedos fosse devidamente feita. Diante dessa situação, solicitou às instâncias competentes do hospital que garantissem uma efetiva limpeza. Ela também elaborou em parceria com a Comissão de Controle de Infecção Hospitalar um manual de como a higienização deveria acontecer. A entrevista com a P4B ocorreu depois da realizada com P4A; segundo seu relato a questão da higienização havia sido sanada, sendo os brinquedos limpos com água e sabão, álcool $70 \%$ ou imerso em solução com hipoclorito.

\section{Discussão}

Notangenteaoprocessodecriação dasbrinquedotecas investigadas, em apenas um hospital (H1) a implantação ocorreu após a promulgação da Lei n. 11.104/05. Além disso, constatou-se que há pouca informação acerca de um possível levantamento das demandas que o espaço atenderia. Isso é acentuado pela carência de um projeto ou de documentos que tratem dos recursos, da organização e de seu funcionamento.
Desse modo, a falta de um planejamento documentado das demandas, dos recursos humanos e materiais, juntamente a um comprometimento pouco palpável dos gestores hospitalares, parecem deixar falhas difíceis de serem sanadas posteriormente. Dessa maneira, a brinquedoteca que apresentou maior carência em termos de pessoal, acessibilidade e oferta de serviços foi justamente aquela em que faltou um projeto que contemplasse pelo menos os aspectos de infraestrutura.

Os dados desta pesquisa vão ao encontro da observação de Dietz e Oliveira (2008) e Magalhães e Pontes (2002), os quais afirmam que, em muitos casos, a implantação da brinquedoteca ocorre sem que haja uma sistematização de como isso deve ser feito, o que pode se estender ao próprio período de manutenção.

Os principais sinalizadores da localização das brinquedotecas pesquisadas parecem ser placas, uma pintura diferenciada e a visualização de seu espaço interior, sendo que somente a do $\mathrm{H} 4$ é situada na área externa do prédio da instituição. Se por um lado essa localização pode favorecer a inserção em um contexto que pouco lembra o hospitalar, por outro impossibilita que parte das crianças tenha acesso a ele.

No que diz respeito ao acervo, observaram-se diferenças tanto na quantidade quanto na diversidade. Contudo, em todos os hospitais foram encontradas brinquedos de faz de conta, blocos de montar e jogos de regras. Os jogos eletrônicos e computadores foram encontrados apenas no $\mathrm{H} 3$, estando ausente o acesso à internet. De acordo com Cunha (2007), a diversificação dos jogos e brincadeiras aumenta as oportunidades de desenvolvimento.

A respeito da organização do acervo lúdico, os resultados encontrados são compatíveis com Cunha (2007), já que os brinquedos com peças pequenas e móveis estavam, em sua maioria, dispostos em lugares supervisionados, enquanto os demais estavam em prateleiras baixas, evitando perda de peças e acidentes.

Acerca da higienização, esta se mostrou compatível com a literatura (Cunha \& Viegas, 2004), sendo um dos aspectos primordiais para a eficácia e sobrevivência de uma brinquedoteca hospitalar, que deve ter uma política de desinfecção dos brinquedos e do espaço (Freitas et al., 2007).

No tocante à infraestrutura, verificou-se que a maioria dos espaços faz uso tanto de iluminação e 
ventilação artificial quanto natural. Esses resultados aliados àqueles sobre o acesso ao material lúdico são indicadores relevantes do alcance dos objetivos a que a brinquedoteca se propôs (Magalhães \& Pontes, 2002).

Todavia, faz-se necessário notar que, provavelmente, algumas dessas brinquedotecas seriam mais eficazes na concretização de seus objetivos se tivessem maior acessibilidade, variedade de brinquedos e livros, um período maior de funcionamento e uma área mais extensa.

Em relação à clientela, ela corresponde, em sua maioria, a pacientes pediátricos internados e seus acompanhantes. 0 fato de parte dessa clientela ser oriunda de comunidades ribeirinhas e indígenas exige da equipe uma atenção perspicaz à bagagem cultural que esta traz, de forma a oportunizar atividades e brinquedos que remetam ao seu cotidiano.

No que respeita a pessoal, as equipes se mostraram distintas no que se refere ao número de membros e à formação teórica, sendo que uma delas carece inclusive de uma equipe voltada à brinquedoteca. Além disso, os dados mostraram a incisiva participação dos profissionais de Terapia Ocupacional e Pedagogia.

Alguns dos fatores que podem estar imbricados nessa composição diferenciada são: história recente da criação das brinquedotecas no Brasil; desconhecimento por parte da sociedade de sua função; e poucos cursos de formação de brinquedista, particularmente fora do eixo sul e sudeste. Falta também uma discriminação das qualificações a serem exigidas da equipe, apesar da promulgação da Portaria 2.261/05, que regulamenta a Lei n. 11.104/05.

Notou-se que em metade dos hospitais falta uma rotina de reuniões de equipe. A literatura tem enfatizado a necessidade de reservar um horário tanto para a formação continuada, quanto para avaliação e planejamento, o que permite a atualização do conhecimento, a manutenção dos aspectos satisfatórios, a resolução de impasses e a busca de soluções (Magalhães \& Pontes, 2002; Dietz \& Oliveira, 2008).

Em relação ao funcionamento, três hospitais oferecem atendimento em dois turnos, sendo que o H4 é o único cujo funcionamento é semanal. Um atendimento descontínuo pode comprometer a obtenção dos objetivos da brinquedoteca, já que dentre outros fatores pode dificultar o estreitamento de vínculo entre a clientela e os profissionais e a realização de uma de suas atividades cotidianas mais prazerosas à criança que é a brincadeira.

As brinquedotecas promovem, além de celebrações de datas festivas, atividades dirigidas, mas sem comprometer o livre brincar. Nesse sentido, verificou-se que elas (as brinquedotecas) são espaços de manifestação das potencialidades lúdicas e de animação sociocultural (Cunha, 2007; Magalhães \& Pontes, 2002; Romano \& Faria, 2008).

\section{Considerações finais}

0 principal aspecto que se destacou neste trabalho foi a infração dos direitos da criança. Apesar de o direito de brincar ser assegurado legalmente pela Constituição Federal e outros dispositivos legais como a Lei n. 11.104/05. Além do descumprimento da legislação, o que se percebe é a ausência das sanções previstas por ela.

Nos hospitais investigados, notou-se a necessidade de resgatar a historicidade da brinquedoteca, já que esta, enquanto instituição, está relacionada aos objetivos a que se propõe, a forma como foi pensada e as condições que estavam postas durante sua implantação. Por outro lado, os resultados indicam que as brinquedotecas têm atendido, em grande parte, as demandas pertinentes a elas, tendo em vista, por exemplo, a pintura diferenciada das demais dependências do hospital, a disposição do acervo lúdico e, principalmente, a promoção do brincar livre.

0 número reduzido de participantes limita a generalização dos resultados, entretanto ratifica o papel da brinquedoteca na humanização da saúde e fomenta a consolidação desse serviço como um dos instrumentos que viabiliza a Política Nacional de Humanização (Brasil, 2004).

Investigações acerca da história, dos espaços e do funcionamento das brinquedotecas hospitalares favorecem um conhecimento científico mais apurado sobre esses novos contextos de desenvolvimento e podem fornecer subsídios para demonstrar a relevância de se garantir na prática direitos já assegurados às criança: a oportunidade de brincar nos hospitais e de ter um atendimento que considere a fase de desenvolvimento em que se encontra. 


\section{Agradecimentos}

Agradecemos à Profa. Vera Maria Barros de Oliveira e ao Prof. Dr. Fernando Augusto Ramos Pontes pelas contribuições à análise e discussão dos dados deste artigo.

\section{Referências}

Brasil. (2004). HumanizaSUS: Política Nacional de Humanização. Documento base para gestores e trabalhadores do SUS. Brasília: Ministério da Saúde. Recuperado em 5 jan. 2008, de http://dtr2001.saude.gov.br/editora/produtos/impressos/folheto/ 04_0923_fl.pdf

Brasil. (2010). Cadastro Nacional de Estabelecimentos de Saúde. Brasília: Secretaria de Atenção à Saúde. Recuperado em 12 fev. 2010, de http://cnes.datasus.gov.br

Carvalho, A. M. A., \& Begnis, G. J. (2006). Brincar em unidades de atendimento pediátrico: Aplicações e perspectivas. Psicologia em Estudo, 11(1), 109-117.

Cunha, N. H. S. (2007). Brinquedoteca: Um mergulho no brincar. (4. ed.). São Paulo: Aquariana.

Cunha, N. H. S., \& Viegas, D. (2004). Brinquedoteca hospitalar: Guia de Orientação. Associação Brasileira de Brinquedotecas. São Paulo: Laramara Editora.

Dietz, K. G., \& Oliveira, V. B. (2008). Brinquedotecas hospitalares, sua análise em função de critérios de qualidade. Boletim da Academia Paulista de Psicologia, 28(1), 100-110.

Freitas, A. P. C. B, Silva, M. C. F., Carvalho, T. C. C., Pedigone, M. A. M., \& Martins, C. H. G. (2007). Brinquedos em uma brinquedoteca: Um perigo real? RBAC, 39(4), 291-294.

Lei n. 11.104. (2005). Brinquedoteca: Um direito das crianças. Brasil: Câmara dos Deputados. Brasília, DF: Recuperado em 10 mar. 2008, de http://www.abrinquedoteca.com.br /artigos_integra2.asp?op=1\&id=3.

Macedo, J. M. M. (2008). A criação de uma brinquedoteca hospitalar com enfoque psicodramático. In D. Viegas (Org.). Brinquedoteca hospitalar isto é humanização. (2. ed., pp. 63-70). São Paulo: Wak Editora.
Magalhães, C. M. C., \& Pontes, F. A. R. (2002). Criação e manutenção de brinquedotecas: Reflexões acerca do desenvolvimento de parcerias. Psicologia Reflexão e Crítica, 15(1), 235-242.

Minayo, M. C. S. (2000). O desafio do conhecimento: pesquisa qualitativa em saúde. (7. ed.). São Paulo: Hucitec.

Mitre, R. M. A., \& Gomes, R. (2007). A perspectiva dos profissionais de saúde sobre a promoção do brincar em hospitais. Ciência \& Saúde Coletiva, 12(5), 1277-1284.

Oliveira, L. D. B., Gabarra, L. M., Marcon, C., Silva, J. L. C., \& Macchiaverni, J. (2009). A brinquedoteca hospitalar como fator de promoção no desenvolvimento infantil: relato de experiência. Revista Brasileira de Crescimento e Desenvolvimento Humano, 19(2), 306-312.

Oliveira, V. B. (2005). A Brinquedoteca em expansão mundial: Breve relato atual. Revista de Psicopedagogia, 22(69), 265-267.

Oliveira, V. B. (2008). O Lúdico na realidade hospitalar. In D. Viegas (Org.). Brinquedoteca hospitalar isto é humanização. (2. ed., pp. 27-32). São Paulo: Wak Editora.

Oliveira, V. B. (2010). 0 brincar da criança hospitalizada e a família: 0 que dizem os trabalhos? In A. M. PérezRamos \& V. B. Oliveira (Org.). Brincar é Saúde- O lúdico como estratégia preventiva. (pp. 41-76). Rio de Janeiro. Wak Editora.

Portaria n. 2.261. (2005, 23 nov.). Aprova o regulamento que estabelece as diretrizes de instalação e funcionamento das brinquedotecas nas unidades de saúde que ofereçam atendimento pediátrico em regime de internação. Brasília, DF: Ministério da Saúde. Recuperado em 8 jan. 2010, de http://dtr2001.saude.gov.br/sas/ PORTARIAS/ Port2005/GM/GM-2261.htm

Romano, B. W., \& Faria, J. (2008). Brinquedoteca do Instituto do Coração do Hospital das Clínicas da Faculdade de Medicina da Universidade de São Paulo. In D. Viegas (Org.). Brinquedoteca hospitalar isto é humanização (2. ed., pp. 141-144). São Paulo: Wak Editora.

Viegas, D., \& Cunha, N. H. S. (2008). Normas para a brinquedoteca hospitalar. In D. Viegas (Org.). Brinquedoteca hospitalar isto é humanização. (2. ed., pp. 11-12). São Paulo: Wak Editora. 